\title{
An assessment of renewable energy generation in a conventional steam power plant with geothermal feedwater preheating
}

\author{
J. Buchta \\ Technical University of Lodz \\ Institute of Electrical Power Engineering \\ 18/22 Stefanowskiego str., 90-924 Lodz (Poland) \\ e-mail: janusz.buchta@p.lodz.pl
}

\begin{abstract}
Hybrid steam power plant with geothermal feedwater preheating enables conversion of low temperature geothermal resources into electricity. The paper presents results of calculation of some performance parameters for $200 \mathrm{MWe}$ fossil power unit associated with geothermal well. The paper gives separation rule of renewable energy from conventional one at hybrid power plant output. An influence of geothermal fluid temperature on hybrid power plant performance is discussed in a study and illustrated in several charts.
\end{abstract}

\section{Key words}

Renewable energy, geothermal energy, steam power plant

\section{Introduction}

Poland is obliged to increase the share of all renewable energy sources (RES) in energy production to $7.5 \%$ in 2010. The growth rate of RES share has been unsatisfactory till now. This situation can be improved by geothermal energy application to produce electricity. Poland has one of the richest low-enthalpy geothermal resources in Europe. Reservoir temperatures vary from 30 to $130^{\circ} \mathrm{C}$ (depths of $1-4 \mathrm{~km}$ ) [1]. The potential of geothermal resources in Poland is estimated at $200 \mathrm{PJ}$ per year and is higher than potential of wind or hydro energy. According to current opinions Polish geothermal resources are intended for district heating or other types of direct uses. Binary cycle plants enable to convert lowenthalpy geothermal resources into electricity, but their efficiency is low and investment costs very high. Lowenthalpy geothermal resources can be used to produce electricity in a hybrid steam power plant i.e. fossil fuel power plant supported by the heat from geothermal well. An idea of a hybrid power plant consist on replacement of a conventional preheater adjacent to the turbine condenser and operating at low temperatures, by the heat exchanger supplied by geothermal energy. Such a power plant could be declared as a RES similarly to steam power plants cofiring fossil fuel with biomass. Green certificates scheme implemented in Poland allows to get an additional income by renewable energy producer in order to return high investment cost of geothermal well.

The paper presents an analysis of the hybrid generation concept in $200 \mathrm{MWe}$ steam power unit. The purpose of a study is to estimate rewnable energy production in a hybrid power plant in dependency from geothermal fluid temperature. An important problem discussed in a study is the way of renewable energy separation from conventional energy produced in a hybrid system.

\section{Geothermal energy conversion into electricity}

Geothermal resources are used to produce electricity in 23 countries. Total installed capacity of all geothermal power plants has reached 8700 MWe [2]. To produce electrical energy, the following geothermal power plants classified in groups have been applied worldwide:

A - non-condensing plants, dry steam plants, wet steam or flash plants, in which steam is used directly in turbines (intended for high-enthalpy resources),

B - binary or organic Rankine cycle plants, in which energy from geothermal fluid is transferred through a heat exchanger to a secondary working fluid (intended for low-enthalpy resources),

$\mathrm{C}$ - combined cycle plants, in which waste water from flash plant is used in binary cycle plant,

D - hybrid plants, which use two fuel types where geothermal fluid temperature is low,

E - total flow plants, in which the impulse energy of nonseparated water mass and steam is used to drive the generator.

More than 500 geothermal power plants are in operation worldwide. The most popular power plants are these of type A $(55 \%)$ and B (40\%) but taking installed capacity of geothermal power plant into consideration, the contribution of power plants of type A is dominating $(92 \%)$ [2]. From the point of view of the ability to 
convert geothermal resources into electricity in Poland, binary cycle plants are widespread. These power plants are characterized by high investment costs (1800-3500 USD), small capacities (100 kW $\div 6 \mathrm{MW})$ and low efficiency $(7 \div 11 \%)$ [2]. A concept of hybrid power plant presented in a study can be an interesting option for the conversion of low-enthalpy geothermal resources into electricity.

\section{Hybrid power plant}

An idea of a hybrid electricity generation was presented in the late 1970s in the USA [3] and recently has been a subject of interest in Germany [4], which has a similar geothermal resources like Poland. The only hybrid power plant in operation is a $35 \mathrm{MWe}$ Honey Lake power plant situated in the USA.

The concept of a hybrid power plant is examined using an example of $200 \mathrm{MWe}$ hard coal fuelled power plant with the steam cycle shown in Fig. 1. In a steam power plant the feedwater for the boiler is preheated in conventional preheaters (labelled from PR1 to PR7) with steam extracted from the turbine. The feedwater temperature behind preheater PR 1 equals $59^{\circ} \mathrm{C}$ (point 15 in Fig. 1 and Tab. I). Preheating process may by partially replaced by geothermal feedwater preheating. An additional heat exchanger (labelled E) can be attached in a bypass to one or more of conventional preheaters. As a result geothermal energy can be used to preheat a feedwater and to produce an electricity in consequence.

In order to analyse the performance of conventional steam power plant (valves $\mathrm{V} 1 \div \mathrm{V} 3$ open, $\mathrm{V} 4 \div \mathrm{V} 5$ closed in Fig. 1) in comparison with hybrid power plant (valves $\mathrm{V} 1 \div \mathrm{V} 3$ closed, $\mathrm{V} 4 \div \mathrm{V} 5$ open), the calorific balance equations have been solved. The simulations for the 200 MWe power plant were done with computer program worked out by author.

The results of mass flow calculations have been validated with actual values. The most important assumptions made for calculations are as follows:

- temperatures, pressures and enthalpies of water and steam in a steam cycle are the same in conventional and hybrid system,

- power output in conventional and hybrid power plant is the same and equals

$$
P_{\text {OUT }}=200 \mathrm{MWe} \text {, }
$$

- turbine internal efficiency is independent from turbine outlet steam flow,

- temperature of geothermal fluid $t_{\text {geo }}$ equals $65^{\circ} \mathrm{C}$, so that conventional preheater PR1 can be fully replaced by the geothermal heat exchanger $\mathrm{E}$.

An important input data and results of mass flow calculations are given in Table I.

\section{Performance of conventional and hybrid power plant}

One of the most important performance parameter characterising power plant cycles is an energetic efficiency, defined as a quotient of the electrical output and the total heat supply. Mass flows of steam and fuel also characterise performance of power plant cycle.

\section{A. Conventional power plant}

In the conventional power plant an energetic efficiency obtained in calculations equals

$$
\eta_{1}=0.393
$$

while steam mass flow at turbine inlet is

$$
\dot{m}_{D 1}=165.2 \mathrm{~kg} / \mathrm{s}=596.4 \mathrm{t} / \mathrm{h}
$$

and coal mass flow is

$$
\dot{m}_{B 1}=22.0 \mathrm{~kg} / \mathrm{s}=79.2 \mathrm{t} / \mathrm{h} \text {. }
$$

\section{B. Hybrid power plant}

In the hybrid power plant an energetic efficiency has to be regarded differently because heat in a hybrid system is supplied in two forms. The energetic efficiency for the heat supplied in fuel is charged by losses in boiler and equals

$$
\eta_{2(F)}=0.382
$$

The energetic efficiency for the heat supplied in geothermal fluid is not charged by losses in boiler and equals

$$
\eta_{2(G)}=0.422
$$

The energetic efficiency for both fuel and geothermal heat equals

$$
\eta_{2}=0.383
$$

Steam mass flow at turbine inlet is

$$
\dot{m}_{D 2}=163.7 \mathrm{~kg} / \mathrm{s}=589.3 \mathrm{t} / \mathrm{h}
$$

and coal mass flow is

$$
\dot{m}_{B 2}=21.8 \mathrm{~kg} / \mathrm{s}=78.5 \mathrm{t} / \mathrm{h} \text {. }
$$

In order to estimate renewable energy production the method of its separation from conventional energy should be proposed. Contribution of conventional energy is proportional to the heat actually utilized in generation of steam in boiler which is not equal to the heat supplied in fuel in the same period because of heat losses in boiler. On the contrary contribution of renewable energy is proportional to the heat supplied in geothermal fluid and is not charged by losses in boiler. The proposed method bases on comparison of heats supplied directly to Rankine cycle from two energy sources. Using this statement separation of renewable energy and conventional energy has been done. In the hybrid power plant under investigation, separating power from renewable resources (geothermal) $P_{R E N}$ and power from conventional resources (fossil fuel) $P_{C O N}$ at the generator output, we get

$$
\begin{aligned}
& P_{R E N}=7.6 \mathrm{MW} \\
& P_{C O N}=192.4 \mathrm{MW}
\end{aligned}
$$

so renewable energy contribution $\left(P_{R E N} / P_{O U T}\right)$ is $3.8 \%$. The heat obtained from geothermal well to supply a heat exchanger $\mathrm{E}$ amounts

$$
\dot{Q}_{G E O}=18.0 \mathrm{MWth} \text {. }
$$

Comparing results of calculations, one can state that energetic efficiency decreases if geothermal heat is introduced to the system, though energetic efficiency $\eta_{2(G)}$ for the geothermal heat conversion increases. 


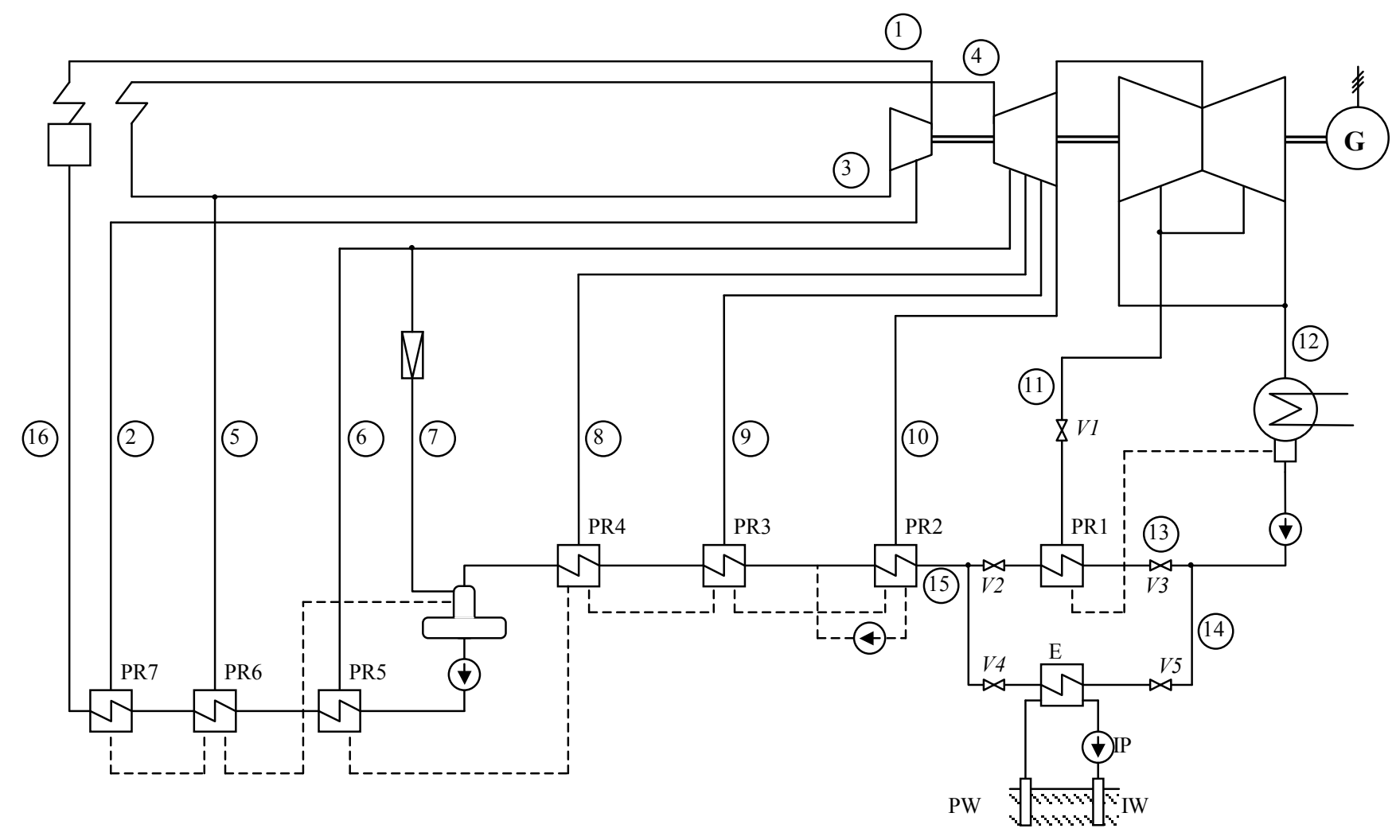

Fig. 1. Scheme of 200 MWe power plant with the geothermal heat exchanger in a bypass to the PR1 preheater. Explanations: PR1-PR7 conventional preheater, PW - production well, IW - injection well, IP - injection pump, E - geothermal heat exchanger.

TABEL I. Thermodynamical properties of water and steam and their mass flows in chosen points of 200 MWe power plant. Points enumeration in accordance with Fig. 1.

\begin{tabular}{|c|c|c|c|c|c|}
\hline \multirow{2}{*}{ Point } & \multirow{2}{*}{$\mathrm{p}[\mathrm{MPa}]$} & \multirow{2}{*}{$\mathrm{t}\left[{ }^{\circ} \mathrm{C}\right]$} & \multirow{2}{*}{$\mathrm{h}[\mathrm{kJ} / \mathrm{kg}]$} & \multicolumn{2}{|c|}{ Mass flow $[\mathrm{kg} / \mathrm{s}]$} \\
\hline & & & & Conventional power plant & Hybrid power plant \\
\hline 1 & 13.0 & 535 & 3433.7 & 165.2 & 163.7 \\
\hline 2 & 4.21 & 387 & 3178.9 & 7.71 & 7.64 \\
\hline 3 & 2.82 & 335 & 3083.8 & 157.4 & 156.0 \\
\hline 4 & 2.52 & 535 & 3543.0 & 145.6 & 144.3 \\
\hline 5 & 2.82 & 335 & 3083.8 & 11.80 & 11.70 \\
\hline 6 & 1.29 & 445 & 3360.3 & 5.49 & 5.44 \\
\hline 7 & 0.60 & 443 & 3360.3 & 2.19 & 2.17 \\
\hline 8 & 0.521 & 331 & 3128.6 & 4.28 & 4.24 \\
\hline 9 & 0.296 & 265 & 2997.9 & 5.23 & 5.18 \\
\hline 10 & 0.138 & 187 & 2847.1 & 8.45 & 8.37 \\
\hline 11 & 0.028 & 67 & 2600.7 & 7.79 & 0 \\
\hline 12 & 0.003 & 24 & 2358.9 & 112.2 & 118.9 \\
\hline 13 & 1.60 & 25 & 96.4 & 120.0 & 0 \\
\hline 14 & 1.60 & 25 & 96.4 & 0 & 118.9 \\
\hline 15 & 1.60 & 59.1 & 247.6 & 120.0 & 118.9 \\
\hline 16 & 18.5 & 242 & 1050.8 & 165.2 & 163.7 \\
\hline
\end{tabular}


The decrease of mass flow can be observed for steam

$$
\Delta \dot{m}_{D}=\dot{m}_{D 1}-\dot{m}_{D 2}=5.3 t / h
$$

as well as fuel savings

$$
\Delta \dot{m}_{B}=\dot{m}_{B 1}-\dot{m}_{B 2}=0.7 t / h
$$

Renewable energy contribution amounts $3.8 \%$ whereas the relative drop of steam flow and fuel consumption in comparison with conventional power plant amounts $0.9 \%$ in both cases. Values of calculated energetic efficiencies also need some explanations. In a hybrid power plant the valve V1 is closed as a consequence of replacing conventional preheater PR1 by geothermal heat exchanger $\mathrm{E}$. This is in opposition to the regenerative feed heat method in Rankine cycle. As a result the energetic efficiency of fuel energy conversion into electricity decreases from 0.393 in conventional power plant to 0.382 in a hybrid one. However, the energetic efficiency of geothermal heat conversion into electricity amounts 0.422 , so it's greater than efficiency achieved for fuel. The reason of such a result is the fact that conversion of geothermal heat isn't charged by losses in boiler, which is in opposition to fuel energy conversion in a boiler furnace. The entire efficiency of both fuel and geothermal heat conversion into electricity in a hybrid power plant $(0.383)$ is less than efficiency received in conventional unit $(0.390)$.

\section{Energy consumption by power plant auxiliaries}

Transformation of conventional power plant into a hybrid one causes changes of mass flows of fuel, steam, air and flue gas. Proportionally to mass flow changes of all mentioned carriers, power demands of auxiliary drives are also changing. As a result of fuel savings, power demand decrease refers to pulverising mills (PM), mill fans (MF), forced draught fans (FDF) and induced draught fans (IDF). The decrease of steam mass flow causes the reduction of energy consumption by feed pump (FP). However the increase of steam mass flow at turbine outlet effects the increase of power demand by cooling water pumps (CP). Mentioned drives have been considered to estimate change of power demand in a hybrid power plant by its auxiliaries. Tabel II includes rated power of motors under examination. An operation load of auxiliary drives is often below their rated capacities even at rated load of power plant. The change of electrical power consumption $\Delta P_{M}$ of specified motors can be estimated as follows

$$
\Delta P_{M}=\frac{\delta \cdot k_{o} \cdot P_{M r}}{\eta_{M}}
$$

where $P_{M r}-$ motor rated power, $k_{o}$ - motor load factor matching motor underloading, $\eta_{M}$ - motor efficiency, $\delta$ relative change of mass flow of the carrier forced or pumped by auxiliary device.

In order to make an estimation, some quantities have been assumed as follows: $k_{o}=0.9, \eta_{M}=0.95$. Calculation results are included in the last column of Tab. II. One can state that total power demand of conventional auxiliary drives slightly decreases in case of the hybrid power plant. However, an extraction and re-injection of brine may require the use of additional pumps with large power consumption. This can reduce an energetic effect of renewable energy generation in a hybrid system. The use of deep-well pump is not required in case of an artesian outflow of brine. Similarly, the use of injection pump is not required in case of low-mineralized brine which can be left above ground surface. It remains a wishful thinking, in fact we can expect power consumption of hundreds of kilowatts depending on depth and flow rate of the geothermal well.

TABEL II. Motor rated power of auxiliary drives and changes of electrical power consumption by motors in a hybrid power plant.

\begin{tabular}{|l|c|c|c|c|}
\hline Drive & $\begin{array}{c}P_{M r} \\
{[\mathrm{~kW}]}\end{array}$ & $\begin{array}{c}\text { Number } \\
\text { of motors }\end{array}$ & $\begin{array}{c}\delta \\
{[\%]}\end{array}$ & $\begin{array}{c}\sum \Delta P_{M} \\
{[\mathrm{~kW}]}\end{array}$ \\
\hline FP & 3150 & 2 & -0.9 & -53.7 \\
\hline PM & 400 & 4 & -0.9 & -13.6 \\
\hline FDF & 500 & 2 & -0.9 & -8.5 \\
\hline IDF & 700 & 2 & -0.9 & -11.9 \\
\hline CP & 1250 & 1 & +6.0 & +70.7 \\
\hline MF & 400 & 4 & -0.9 & -13.6 \\
\hline TOTAL & & & -30.8 \\
\hline
\end{tabular}

\section{Influence of geothermal fluid temperature on hybrid power plant performance}

Calculations presented in previous section refer to constant geothermal fluid temperature of $65^{\circ} \mathrm{C}$. The next step in a hybrid power plant study is an investigation of an influence of geothermal fluid temperature on power plant performance. If geothermal fluid temperature increases above $65^{\circ} \mathrm{C}$ then the mass flow of steam bled from the turbine to preheater PR2 can decrease. When temperature of geothermal fluid reaches $105^{\circ} \mathrm{C}$ then preheater PR2 is fully replaced by heat exchanger $\mathrm{E}$ and the mass flow of steam in point 10 (Fig. 1) reduces to 0 . When geothermal fluid temperature is lower then $65^{\circ} \mathrm{C}$ then heat exchanger E should be placed serially between preheater PR1 and condenser. If geothermal fluid temperature decreases below $65^{\circ} \mathrm{C}$ then the mass flow of steam bled from the turbine to preheater PR1 have to increase. When temperature of geothermal fluid reaches $30^{\circ} \mathrm{C}$ then heat exchanger E doesn't preheat feedwater and all performance parameters of hybrid power plant are the same like in conventional power plant. Operation of hybrid power plant with geothermal well of temperature varying from $30^{\circ} \mathrm{C}$ to $105^{\circ} \mathrm{C}$ requires control of steam flows bleeding from turbine to preheaters PR1 and PR2.

Performance of a hybrid power plant associated with geothermal well supplying fluid of varying temperature from $30^{\circ} \mathrm{C}$ to $105^{\circ} \mathrm{C}$ has been investigated. The results of calculations are presented in Fig. 2-10. The following performance parameters have been investigated:

- steam mass flows at turbine inlet and outlet (Fig. 2),

- mass flows of steam extracted from turbine for feedwater preheating in preheaters PR1-PR2 (Fig. 3),

- energetic efficiencies of heat in fuel conversion, geothermal heat conversion and entire efficiency (Fig. 4), 


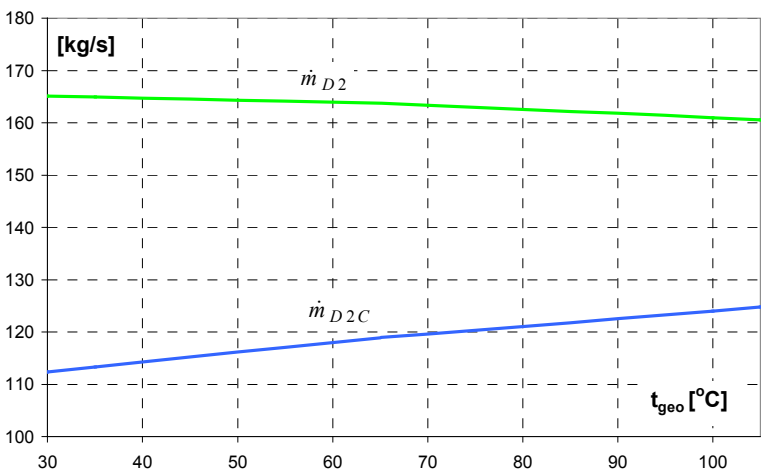

Fig. 2. Steam mass flows at turbine inlet $\dot{m}_{D 2}$ and turbine outlet $\dot{m}_{D 2 C}$ in dependency from geothermal fluid temperature $t_{\text {geo }}$.

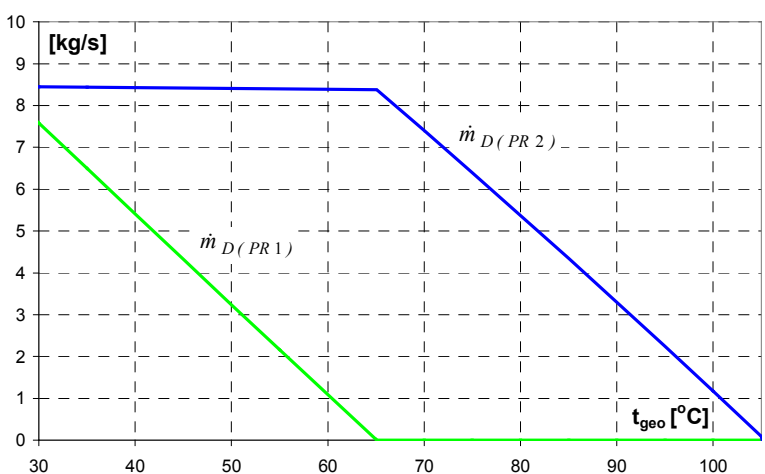

Fig. 3. Mass flows $\dot{m}_{D(P R 1)}$ and $\dot{m}_{D(P R 2)}$ of steam extracted from turbine for feedwater preheating in preheaters PR1 and PR2 in dependency from geoth. fluid temperature $t_{g e o}$.

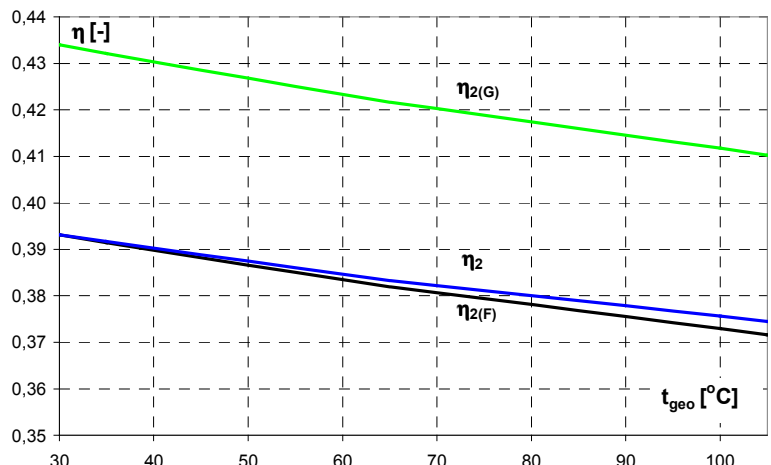

Fig. 4. Energetic efficiencies of heat in fuel conversion $\eta_{2(F)}$, geothermal heat conversion $\eta_{2(\mathrm{G})}$ and entire efficiency $\eta_{2}$ as a dependency from geothermal fluid temperature $t_{g e o}$.

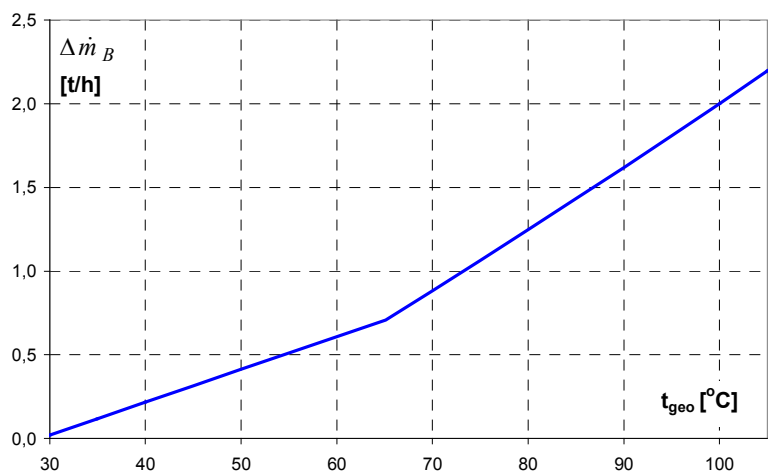

Fig. 5. Fuel savings $\Delta \dot{m}_{B}$ in a hybrid power plant as a dependency from geothermal fluid temperature $t_{\text {geo }}$.

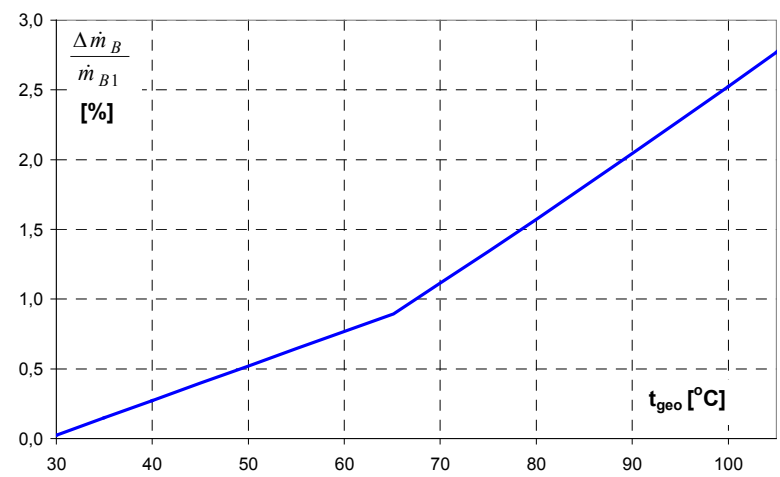

Fig. 6. Quotient of fuel savings $\Delta \dot{m}_{B}$ in hybrid power plant and fuel consumption $\Delta \dot{m}_{B 1}$ in conventional power plant in dependency from geothermal fluid temperature $t_{g e o}$.

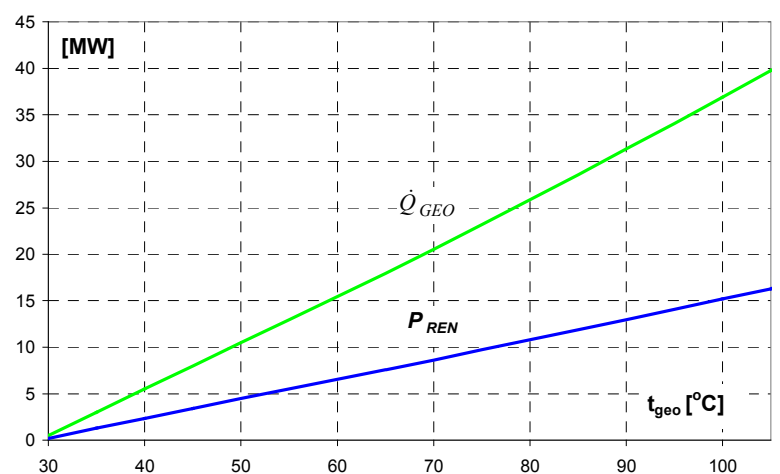

Fig. 7. Required amount of heat obtained from geothermal well $Q_{G E O}$ to produce renewable energy $P_{R E N}$ in a hybrid power plant in dependency from geothermal fluid temperature $t_{\text {geo }}$.

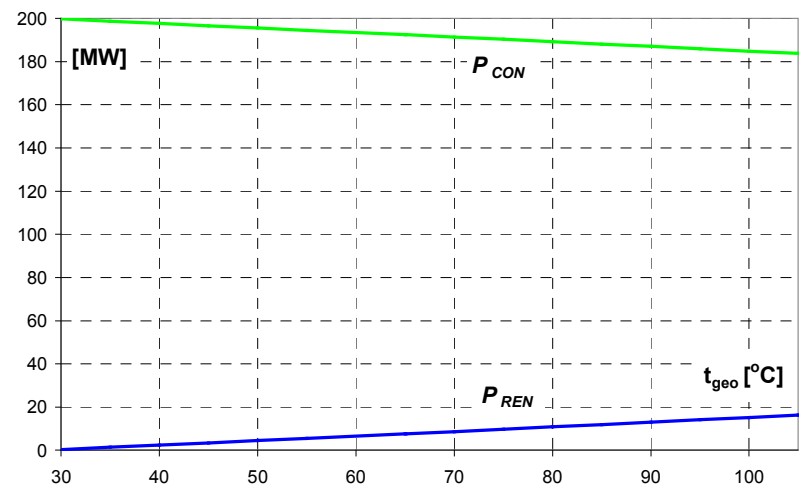

Fig. 8. Generation of conventional power $P_{C O N}$ and renewable power $P_{R E N}$ in a hybrid power plant in dependency from geothermal fluid temperature $t_{g e o}$.

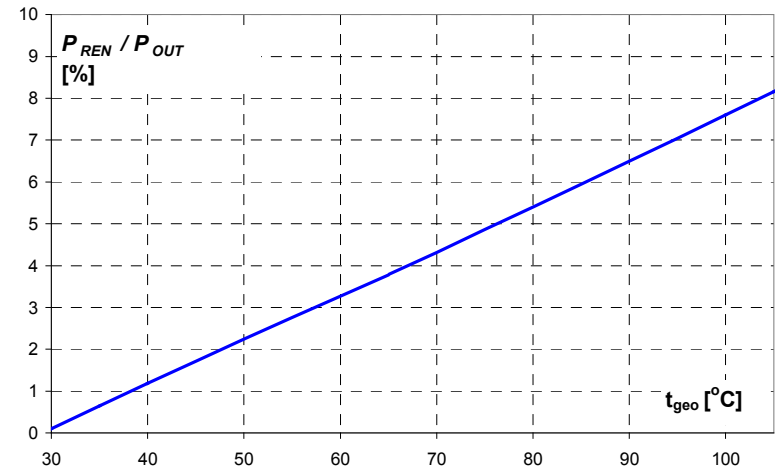

Fig. 9. Contribution of renewable power $P_{R E N}$ in total power output $P_{\text {OUT }}$ of hybrid power plant in dependency from geothermal fluid temperature $t_{g e o}$. 


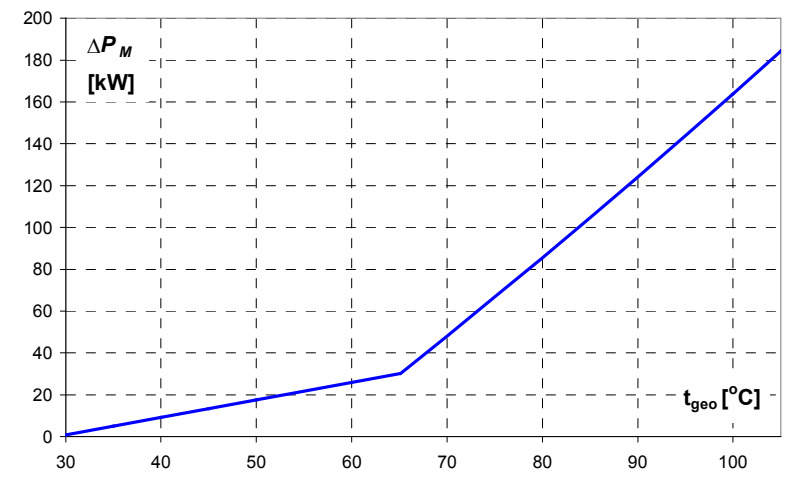

Fig. 10. The decrease of power consumption $\Delta \mathrm{P}_{\mathrm{M}}$ by conventional auxiliary drives in hybrid power plant as dependency from geothermal fluid temperature $t_{g e o}$.

- fuel savings in a hybrid power plant (Fig. 5) as well as relative fuel savings (Fig. 6),

- required amount of heat obtained from geothermal well for feedwater preheating (Fig. 7),

- amount of produced conventional and renewable power (Fig. 7-8) as well as renewable energy contribution in total generation (Fig. 9),

- change of power consumption by conventional auxiliary drives (Fig. 10).

Gradients of some curves presented in Fig. 2-10 change at geothermal fluid temperature of $65^{\circ} \mathrm{C}$. It is caused by different values of turbine internal efficiencies between bleeders supplying preheaters PR1, PR2 and turbine outlet. Analysing fuel savings (Fig. 5-6) in a hybrid power plant one can state that geothermal fluid temperature above $65^{\circ} \mathrm{C}$ gives better results. It's a hint how to place a heat exchanger $\mathrm{E}$ in power plant scheme in case of higher temperature of geothermal fluid.

\section{Conclusions}

Preliminary evaluation made for a hybrid power plant suggest some conclusions expressed below.

- The concept of a hybrid power plant sets up technological problems but requires detailed analysis of its economical effectiveness. Green certificates scheme implemented in Poland allows to hope that transformation of a conventional power plant into a hybrid one can be cost-effective.

- In author's opinion, contribution of conventional energy in a hybrid system under investigation is proportional to the heat actually utilized in generation of steam in boiler, which is lower than heat supplied in fuel in the same period because of heat losses in boiler. On the contrary contribution of renewable energy is proportional to the heat supplied in geothermal fluid and is not charged by losses in boiler.

- Change for worse of the energetic efficiency in a hybrid power plant results in less fuel savings $(0.9 \%$ for $\left.t_{\text {geo }}=65^{\circ} \mathrm{C}\right)$ than renewable energy contribution $(3.8 \%$ respectively). So that, an ecological effect of $\mathrm{CO}_{2}$ emissions reduction becomes controversial.

- Higher level of fuel saving can be achieved in power plants of lower efficiency. This remark especially refers to boilers of low efficiency. The efficiency of the boiler in the power plant under examination has been relatively high and equal 0.915. Therefore, the concept of hybrid power plant might be more effective for older power plants.

- The case of hybrid power plant under examination with geothermal fluid temperature of $t_{\text {geo }}=65^{\circ} \mathrm{C}$ is possible to apply with Polish geothermal resources. Geothermal facilities operating in Poland achieve similar brine temperatures and geothermal well flow rates as required in a hybrid power plant [1]. In case of insufficient geothermal well flow rate, simultaneous operation of both heat exchangers PR1 and E should be considered (parallel or serial) as well as association of geothermal well with steam power plant of lower capacity.

- Contribution of renewable energy produced in a hybrid power plant increases with temperature growth of geothermal fluid up to $8.1 \%$ for $t_{g e o}=105^{\circ} \mathrm{C}$. Higher level of renewable energy contribution ensures better profitability of hybrid power plant.

- Assuming annual full load hours at $\tau_{a}=6000 \mathrm{~h} / \mathrm{a}$, an annual yield of renewable energy $E_{a R E N}$ in a hybrid power plant associated with geothermal well providing fluid with temperature of $t_{\text {geo }}=65^{\circ} \mathrm{C}$ amounts

$E_{a R E N}=P_{R E N} \cdot \tau_{a}=7.6 \mathrm{MW} \cdot 6000 \mathrm{~h} / \mathrm{a}=45.5 \mathrm{GW} \cdot \mathrm{h} / \mathrm{a}$.

Renewable energy produced in a hybrid power plant is a source of additional income from green certificates sale by the power plant owner.

- Further investigations under hybrid power plant require estimation of influence on steam turbine internal efficiency due to the steam flow increase at turbine outlet.

- Expanding the concept of hybrid power plant, CHP systems should be considered. Similarly, the hybrid system fuelled by biomass should be considered as the facility producing purely renewable energy.

\section{Acknowledgement}

The author is grateful to Polish Ministry of Science and Higher Education for financial support of the research.

\section{References}

[1] B. Kepinska, "Current geothermal activities and prospects in Poland - an overview", Geothermics, 32 (2003), pp. 397-407.

[2] J.W. Lund, "The basics of geothermal power conversion", Presentation at the conference "Renewables Bonn 2004, Day of Geothermal Power".

[3] H. Khalifa, R. DiPippo, J. Kestin, "Geothermal preheating in fossil-fired steam power plants", Proceedings of the $13^{\text {th }}$ Intersociety Energy Conversion Engineering Conference, 2 (1978), pp. 1068-1073.

[4] M. Bruhn, "Hybrid geothermal-fossil electricity generation from low enthalpy geothermal resources: geothermal feedwater preheating in conventional power plants", Energy, (27) 2002 , pp. $329 \div 346$. 